\title{
Implementation and evaluation of a novel research education rotation for Royal College of Physicians and Surgeons emergency medicine residents
}

\author{
Riyad B. Abu-Laban, MD, MHSc ${ }^{*}$; Sandra Jarvis-Selinger, $\mathrm{PhD}^{*}$; Lana Newton, BAA ${ }^{\ddagger}$; \\ Brian Chung, $\mathrm{MD}^{*} \S$
}

\section{ABSTRACT}

Royal College of Physicians and Surgeons (RCPS) emergency medicine (EM) residents must complete a scholarly project; however, significant variation exists in Canadian EM resident research education and facilitation. We developed and implemented a novel mandatory research education rotation for RCPS EM residents intended to increase knowledge, faculty/resident collaborations, and, ultimately, scholarly output. This 4-week rotation took place in the fall of 2011 and consisted of 37 faculty-led didactic, critical appraisal, and workshop seminars. Exposure to faculty research and resulting opportunities and the development of resident research projects were integrated into the rotation. Twelve participating residents completed daily evaluations and took part in an exit focus group analyzed using a constant comparative method. Knowledge acquisition was assessed with a pre/post comprehensive examination instrument evaluated by a paired $t$-test. Evaluations indicated generally high satisfaction throughout the rotation. Focus group analysis indicated that residents felt two important but competing goals existed: developing a research project and developing critical appraisal skills. The research knowledge of all participants improved significantly (mean/SD examination change $+35.4 \% /+10.4 \%$, range $+20.0 \%$ to $+53.6 \%, p<$ 0.001 ), and several new resident/faculty research collaborations arose from the rotation. A rotation of this nature is an efficient and effective means to increase research and critical appraisal knowledge and faculty/resident collaborations. As a result of our positive experience, the rotation will continue annually and has been expanded to include pediatric EM fellows. Longitudinal tracking of the participating trainee cohort will remain ongoing to assess the scholarly output impact of the rotation.

\section{RÉSUMÉ}

Les résidents en médecine d'urgence (MU) du Collège royal des médecins et chirurgiens du Canada doivent réaliser un projet de recherche, mais il existe des différences importantes dans l'enseignement en matière de recherche et la facilitation de la démarche, au pays. Nous avons donc élaboré et mis en oeuvre un nouveau stage de formation obligatoire en recherche, à l'intention des résidents en MU du Collège afin d'accroître le bagage de connaissances, le nombre de projets de collaboration entre résidents et membres du corps professoral, et, finalement, la production de travaux de recherche. Ce stage d'une durée de 4 semaines a été expérimenté à I'automne de 2011 et il consistait en la présentation de 37 séminaires didactiques, séances d'évaluation critique et ateliers, sous la direction de professeurs. L'exposition aux travaux de recherche des membres du corps professoral et les possibilités de recherche qui en ont découlé, de même que l'élaboration de projets de recherche par les résidents, étaient tous des éléments intégrés dans le contenu du stage. Douze résidents participant au programme ont rempli les fiches d'évaluation quotidienne et ont fait partie d'un groupe de réflexion à l'issue de l'expérience, puis analysé les résultats à l'aide d'une méthode de comparaison constante. L'acquisition des connaissances a été évaluée au moyen d'un instrument d'examen global avant et après le stage à I'aide du test de Student pour échantillons appariés. Les évaluations ont indiqué un degré de satisfaction généralement élevé tout au long du stage. En outre, l'analyse du groupe de réflexion a révélé que les résidents avaient perçu l'existence de deux objectifs importants mais concurrents, soit l'élaboration d'un projet de recherche et l'acquisition d'habiletés en matière d'évaluation critique. Tous les participants ont indiqué que leur bagage de

From the *Department of Emergency Medicine, University of British Columbia; †Vancouver Health Research Institute Centre for Clinical Epidemiology \& Evaluation; †eHealth Strategy Office, Faculty of Medicine, University of British Columbia; and §RCPS Emergency Medicine Residency Program, University of British Columbia, Vancouver, BC.

Correspondence to: Dr. Riyad B. Abu-Laban, Department of Emergency Medicine, University of British Columbia, 910 West 10 th Avenue, Room 3300, Vancouver, BC V5Z 1M9; abulaban@mail.ubc.ca.

This article has been peer reviewed.

(c) Canadian Association of Emergency Physicians 
connaissances sur la recherche avait considérablement augmenté (variation moyenne/écart type: $+35.4 \% /+10.4 \%$; plage: $+20.0 \%$ à $+53.6 \%$; $p<0.001$ ), et le stage a donné lieu à l'élaboration de plusieurs nouveaux projets de collaboration entre résidents et membres du corps professoral. $\mathrm{Ce}$ genre de stage est un moyen efficace et efficient d'acquisition de connaissances sur la recherche et l'évaluation critique et de réalisation de projets de recherche associant professeurs et résidents. Compte tenu des résultats favorables de l'expérience, le stage sera offert chaque année et il a été étendu aux collègues en MU pédiatrique. Le suivi longitudinal de la cohorte de stagiaires participants se poursuivra afin que soit évaluée l'incidence du stage sur la production de travaux de recherche.

Keywords: emergency medicine, research education, residency, resident
Integrating research education into emergency medicine (EM) residency training has been advocated since the early years of the specialty. ${ }^{1}$ Beyond societal benefits, acquiring research skills and experience is an essential component of academic career development. ${ }^{2}$ However, although a significant proportion of EM residents express interest in academia during the early years of their training, this enthusiasm frequently wanes. ${ }^{3}$ Evidence exists that formal research educational programs for EM residents can be successful ${ }^{4}$ and that when scholarly projects are required of residents, meaningful contributions to the medical literature result.

The Royal College of Physicians and Surgeons (RCPS) Specialty Training Requirements in Emergency Medicine require research education and completion of a scholarly project during the 5 -year residency "suitable for peerreviewed publication or presentation at a national academic meeting." ${ }^{6}$ However, an informal e-mail survey of all RCPS EM program directors in Canada, carried out by the lead author in 2010, revealed significant site-based variation in the nature of $\mathrm{EM}$ resident research education and facilitation and the degree to which a formal curriculum is provided.

\section{RATIONALE}

Historically, RCPS EM resident research education at the University of British Columbia (UBC) has involved unstandardized teaching at various venues, including research rounds, journal clubs, academic rounds, and a limited number of seminars. This contrasts to a growing trend toward goal-based clinical education ${ }^{7}$ and an increasing understanding that the development of nonclinical resident competencies such as teaching skills benefits from a formal structure and curriculum. ${ }^{8,9}$

The potential to improve UBC EM resident research education was identified in a 2007 RCPS accreditation. For many years, the possibility of incorporating a "research block" into the residency program had been discussed. The development of this was catalyzed in 2009 by the establishment of a full department of emergency medicine at UBC, the resulting amalgamation of faculty under one academic entity, and the recent successful local launch of a resident-as-teacher rotation. In 2010, the UBC Department of Emergency Medicine made the decision to establish a mandatory RCPS EM residency research rotation. We believed that the creation of such a rotation would be an efficient and effective means to increase resident research knowledge, faculty/resident research collaborations, and, ultimately, residents' scholarly output.

\section{INNOVATION DESCRIPTION}

A four-person curriculum committee was struck involving EM research leaders at UBC. The committee reviewed information from the aforementioned environmental scan of Canadian RCPS EM program directors, polled the UBC RCPS EM residents for their perspectives, and reviewed information from established courses and textbooks. A curriculum was then developed consisting of 29 didactic seminars led by 21 faculty members (Table 1 ) and an additional 8 critical appraisal and project development workshop sessions led by the rotation director. We relied on the content expertise of faculty members and did not prespecify learning outcomes for the seminars and sessions. Exposure to faculty members' research and resulting opportunities was formally integrated into the rotation through presentations by each seminar leader at the end of the didactic session. Residents were expected to establish and advance individual research projects over the course of the rotation and present their progress at a formal event at the end of the rotation. 


Table 1. NERD Block didactic seminars
Week 1: Foundations
The Spirit of Inquiry and the Role of Research in EM
Ten Common Errors in EM Research
Assumptions and Values in Medical Research
Identifying an Area of Interest
Searching the Literature
Critical Appraisal
Formulating a Hypothesis and Defining a Research Question
Overview of Study and Methodology Options
Week 2: Study Considerations and Designs
Outcome Measures
Medical Record Reviews
Interviews and Focus Groups
Surveys
Case-Control and Cohort Studies
Randomized Controlled Trials
Sampling, Randomization, and Blinding
Systematic Reviews
Clinical Decision Rules
Week 3: Data Sources, Analytic Issues, and Study Threats
Registries and Databases from Prior Studies
Administrative Databases and QI/QA Initiatives
Data Types, Descriptive Statistics, and Scales
Basic and Advanced Statistics, Data Coding, and Use of Statistical
Software
Bias, Association and Causation, Power, and Sample Size
Study Tracking, Recruitment Issues, Protocol Violations,
Reliability, and Validity
Week 4: Ethical Issues, Study Mechanics and Research
Dissemination
The Tri-Council Policy and the REB Submission and Review
Process
Consent and Unique Ethical Considerations in EM and Critical Care
Grantsmanship, Timelines, Budgets, and Funding Opportunities
Knowledge Translation
Managing Research Teams, Authorship Decisions, and the
Publication Process
Abstracts and Posters
EM=emergency medicine; QA = quality assurance; Ql = quality improvement; REB =
Research Ethics Board.

The rotation was playfully titled the "NERD Block" (Novel Education in Research and Design Block) and was delivered to 12 participating residents from 9 am to $4 \mathrm{pm}, 4$ days a week for a 4 -week period from October 24 to November 18, 2011. Participants were excluded from the rotation on their academic day, during which regular rounds and seminars took place. Participants completed daily evaluations and participated in an exit focus group analyzed using a constant comparative method. The focus group was facilitated by one of the investigators (L.N.) and used a semistructured interview protocol. The data were subsequently analyzed by two investigators trained in qualitative methodologies (L.N. and S.J.S.) using a constant comparative method. This method, closely associated with grounded theory, can be used to analyze focus group data even when a study is hypothesis driven. ${ }^{10}$ This approach facilitated open coding and the generation of important themes about the NERD Block. Knowledge acquisition was assessed with a pre/post comprehensive examination instrument evaluated by a paired $t$-test. The research component of the initiative was approved by the UBC Research Ethics Board, and informed consent was obtained from all participants.

\section{DISCUSSION}

This rotation was novel in its delivery of a wideranging curriculum during a dedicated 4-week period, use of a broad spectrum of faculty, encouragement of faculty/resident collaborations, and integration of critical appraisal and project development with didactic education. Evaluations indicated generally high satisfaction throughout the rotation, although rating differences were found between seminars regarding content, applicability, and presenter and global factors. Topics with less immediately obvious relevance, such as qualitative methodologies and knowledge translation, tended to receive poorer evaluations. Adjustments were made in real time to the course curriculum as a result of participant feedback, the most noteworthy of which was that the time spent on critical appraisal of the medical literature was significantly expanded.

The focus group analysis identified six themes of importance: goals, course structure, content, presenters, identifying with the researcher role, and course director. Perspectives that will be helpful in guiding future iterations of the rotation were obtained under each theme. We found that participants approached the rotation with differing individual goals depending on their prerotation knowledge. Broadly speaking, participants felt that two important but competing goals existed: developing a research project and developing critical appraisal skills. The research knowledge of all participants improved significantly (mean/SD examination change $+35.4 \% /+10.4 \%$, range $+20.0 \%$ to $+53.6 \%, p<0.001)$; however, it is conceivable that test-induced learning was a factor in 
this finding, and several new faculty/resident research collaborations arose from the rotation. Although establishing a causal relationship between the rotation and research productivity will be difficult, longitudinal tracking of the participating trainee cohorts will remain ongoing in an effort to assess the scholarly output impact of the rotation.

As a result of our positive experience, the NERD Block will continue annually at UBC for Year 2 RCPS residents and has been expanded to include pediatric EM fellows. The critical appraisal component of the curriculum will be broadened and formalized in the second year of the rotation, and involvement of pediatric EM faculty will be increased to better reflect the joint nature of the initiative.

\section{SUMMARY}

We developed and implemented a novel mandatory research education rotation for RCPS EM residents that has since expanded to include pediatric EM fellows. A rotation of this nature is an efficient and effective means to meet the RCPS EM specialty training requirements through increasing research and critical appraisal knowledge and faculty/trainee collaborations. In addition, it is our hope that the rotation will lead to increased research productivity by participating trainees and, in doing so, facilitate ongoing academic career development.

Acknowledgement: We gratefully acknowledge Drs. Jeff Brubacher, Garth Hunte, and Rob Stenstrom for their participation on the curriculum committee; Ms. Mira Pandya for her administrative excellence; UBC Department of Emergency Medicine Head Dr. Jim Christenson for his support and guidance; the residents in the inaugural year of the NERD Block for their valuable feedback; and the 21 faculty members, without whom the rotation could not have been established.
Competing interests: Support for the research component of this initiative was provided by a 2011 Faculty Development Initiatives Grant from the Office of Faculty Development and Educational Support in the UBC Faculty of Medicine.

\section{REFERENCES}

1. Jones J, Dougherty J, Cannon L, et al. Teaching research in the emergency medicine residency curriculum. Ann Emerg Med 1987;16:347-53, doi:10.1016/S0196-0644(87) 80186-5.

2. Stead LG, Sadosty AT, Decker WW. Academic career development for emergency medicine residents: a road map. Acad Emerg Med 2005;12:412-6, doi:10.1111/j.1553-2712. 2005.tb01541.x.

3. Neacy K, Stern SA, Kim HM, et al. Resident perception of academic skills training and impact on academic career choice. Acad Emerg Med 2000;7:1408-15, doi:10.1111/ j.1553-2712.2000.tb00499.x.

4. Rydman RG, Zalenski RJ, Fagan JK. An evaluation of research training in a large residency program. Acad Emerg Med 1994;1:448-53, doi:10.1111/j.1553-2712.1994. tb02525.x.

5. Holmes JF, Sokolove PE, Panacek EA. Ten-year experience with an emergency medicine resident research project requirement. Acad Emerg Med 2006;13:575-9, doi:10.1111/ j.1553-2712.2006.tb01011.x.

6. Royal College of Physicians and Surgeons Specialty Training Requirement in Emergency Medicine (2010). Available at: http://rcpsc.medical.org/information/index.php?specialty $=122$ \&submit=Select (accessed May 29, 2012).

7. Tintinalli JE, Shofer F, Biese K, et al. Toward a new paradigm goal-based residency training. Acad Emerg Med 2011;18 Suppl 2:S71-8, doi:10.1111/j.1553-2712.2011.01174.x.

8. Farrell SE, Pacella C, Egan D, et al. Resident-as-teacher: a suggested curriculum for emergency medicine. Acad Emerg Med 2006;13:677-9, doi:10.1111/j.1553-2712.2006.tb01031.x.

9. Patocka C, Meyers C, Delaney S. Residents-as-teachers: a survey of Canadian specialty programs. Can 7 Emerg Med 2011;13:319-24.

10. Onwuegbuzie AJ, Dickinson WB, Leech NL, Zoran AG. A qualitative framework for collecting and analyzing data in focus group research. Int 7 Qual Methods 2009;8(3):1-21. 